\title{
LA CONSTANCIA DEL
}

MOVIMIENTO. Olga

\section{Tokarczuc. Premio nobel}

\section{DE LITERATURA 2018}

The constancy of movement. Olga Tokarczuc. 2018 Nobel prize in literature

\section{Aldo Vivar Mendoza ${ }^{1}$}

\section{ReSUMEN}

La literatura centroeuropea está llena de sorpresas. Olga Tokarczuk es una de ellas. Casi desconocida para los lectores hispanoamericanos, posee una obra cautivante que combina narrativa y ensayo, realidad y magia, movimiento y constancia.

Palabras claves: Premio Nobel, literatura, Polonia.

\section{Abstract}

Literature from Central Europe is full of surprises. Olga Tokarczuk is an example of this. Virtually unknown for Spanish speaking readers, her works merge narrative and essay, reality and magic, movement and invariance.

Keywords: Nobel Prize, literature, Poland.

1 Profesor auxiliar. Facultad de Medicina, Universidad Peruana Cayetano Heredia.

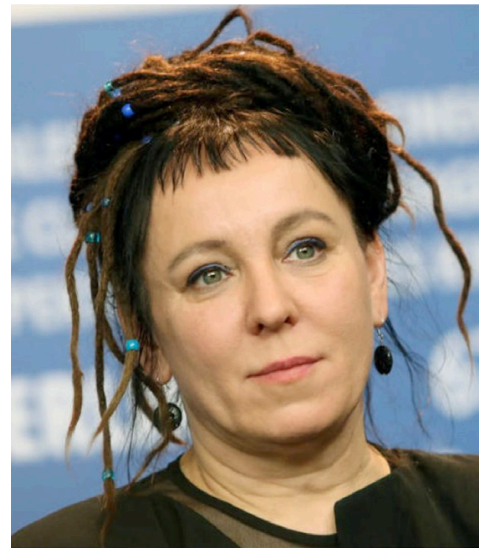

Olga Tokarczuc

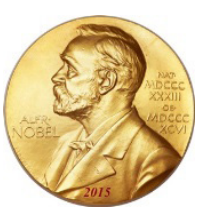


acoso sexual. La denuncia fue hecha por el diario Dagens Nyheter. Resulta que Arnault es esposo de la académica Katarina Frostenson y ambos regentaban un club literario llamado Forum que ha recibido financiamiento de la Academia Sueca.

Para empeorar las cosas, se acusó también a Arnault de filtrar los nombres de los ganadores del Premio Nobel hasta en siete ocasiones. Este hecho no solo tiene serias implicancias éticas sino también económicas, los días previos a la entrega del premio en octubre las casas de apuesta viven una gran turbulencia y mucho dinero esta en juego.

La denuncia periodística motivó unainvestigación fiscal pero el escándalo mediático generó una renuncia en cadena, empezando por académicos que abogaban por la expulsión de Frostenson, luego la involucrada y hasta la secretaria permanente, Sara Danius, primera mujer en ocupar este cargo. Esto ocurrió en abril del 2018, mes clave en la Academia cuando se seleccionan a los candidatos preliminares -una lista larga de quince a veinte nominados-, para luego en el mes de mayo se obtenga una lista corta de cinco candidatos y cuyas obras serán leídas por los académicos durante el verano boreal, después del cual se reunirán en setiembre para decidir los méritos de cada nominado. Como es costumbre, el ganador es elegido los primeros días de cada octubre.

Como consecuencia de este escándalo, se tuvo una tragedia escandinava de pugnas y delitos digna de Shakespeare. La Academia Sueca canceló la otorgación del premio y ordenó una reorganización de sus estatutos, entre ellos la imposibilidad de la renuncia al cargo de académico, así como de sus miembros.

Tiempo después, el Tribunal de Apelación de Estocolmo encontró culpable de los cargos de violación a Arnault.
Salvo los años afectados por las dos Guerras Mundiales, no se había vivido una crisis que generara interrupciones en la entrega de premios.

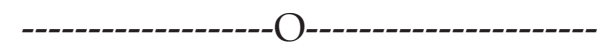

Olga Tokarczuc, Premio Nobel de Literatura 2018, es vegetariana, feminista e iconoclasta, un referente cultural. Es habitual en su aspecto el uso de la plica polónica, una forma de usar el cabello aglutinado y apelmazado, formando trenzas que es típica de Polonia y otras zonas de Europa Central, costumbre que viene desde la Edad Media. Todos estos atributos hacen que no pase desapercibida en una sociedad con una fuerte tradición católica y nacionalista. En una oportunidad, a raíz de la recepción de un premio literario, dio declaraciones en la televisión polaca mencionando "horribles actos de colonización" de su país, contraviniendo la extendida autopercepción de que Polonia ha padecido sufrimiento y ha sobrevivido a siglos de opresión. Por tal motivo, fue declarada por la ultraderecha polaca como targowiczanin, un término antiguo para traidora. ${ }^{(1)}$

Casi desconocida para el público hispanoamericano, Olga Tokarczuc es una escritora súper ventas en Polonia. Al momento de recibir el Premio Nobel, octubre 2019, solo tenía publicados dos libros en español, uno de ellos ya descatalogado, y se sabía que en noviembre de 2019 saldría a la venta en España la novela Los Errantes, que había recibido el Premio Man Booker en Inglaterra el 2018. ${ }^{(2)}$ Como siempre, el Nobel revela autores interesantes y, sobre todo, una historia de vida por descubrir.

1 https://www.theguardian.com/books/2018/apr/20/olgatokarczuk-interview-flights-man-booker-international. Accedido el 23 de febrero del 2020

2 https://www.anagrama-ed.es/novedades/archivo/20191101 accedido el 15 de octubre del 2019 
Olga Tokarczuc, nació en Sulechow en 1962, una localidad al sur de Polonia. Sus padres eran profesores de escuela, su padre además era bibliotecario. En aquella biblioteca escolar, Olga forjó su apetito por los libros y el conocimiento.(3) Posteriormente, ingresó a la Universidad de Varsovia para estudiar psicología, ejerciendo la carrera en un hospital psiquiátrico. Tokarczuc se considera a sí misma una seguidora del legado de Carl Jung.

En 1993, publicó su primer libro Podróz ludzi Ksiegi (El viaje de la gente del libro), una historia ambientada en el siglo XVII entre España y Francia, donde los personajes se embarcan en la búsqueda de un misterioso libro. Esta obra mereció el premio de los editores polacos por el mejor debut 1993-1994. Dos años después publicó su segunda novela E. E., donde su personaje Erna Eltzner, una niña que creció en la frontera germano polaca, tiene el poder de ser médium, tema que demuestra el interés de la autora por lo sobrenatural.

Con su tercera novela Prawiek $i$ inne czasy (Antaño y otros tiempos), Tokarczuc consiguió su consagración:

Antaño es un lugar situado en el centro del universo. Para cruzar Antaño de norte a sur, a paso ligero, sería necesaria una hora. Lo mismo, de este a oeste. $Y$, si alguien quisiera rodear Antaño, a paso lento, observándolo todo con detenimiento y atención, tardaría un día entero, desde la mañana hasta la noche. Por la frontera norte de Antaño discurre un camino que va de Taszów a Kielce, transitado y peligroso, porque provoca ansia de viajes. Esta frontera la protege el arcángel san Rafael.

[...]

3 https:/ / www.nobelprize.org / prizes / literature/2018/tokarczuk/facts/ accedido el 10 de enero del 2020
La frontera sur la marca el pueblo de Jeszkotle, con su iglesia, su asilo de ancianos y sus casas bajas que circundan una plaza llena de barro. Este pueblo es amenazador, porque engendra el deseo de poseer y de ser poseído. Por este lado, Antaño está protegido por el arcángel San Gabriel.

La frontera oeste de Antaño está jalonada por unos prados húmedos y cercanos al río, algo de bosque y un palacio. Junto a este hay una caballeriza, donde cada caballo vale tanto como todo Antaño. Los caballos pertenecen al amo y los prados al cura. El peligro de la frontera oeste es el pecado de la soberbia. Esta frontera está protegida por el arcángel san Miguel.

En el este, la frontera de Antaño sigue el curso del río Blanco, que separa sus tierras de las de Taszów. Luego el Blanco tuerce en dirección al molino, y la frontera continúa sola, por las praderas y entre los arbustos de alisos verdes. El peligro que amenaza este lado es la estupidez que procede de las ganas de dárselas de inteligente. Esta frontera la vigila el arcángel san Uriel.

Antaño, un pueblo imaginario de Polonia, está poblado por seres excéntricos. La novela es una saga familiar que inicia en 1914 y tiene que ver con la historia de Polonia en el siglo XX. Escrita en episodios, algunos de ellos de menos de una carilla de extensión, cuenta las microhistorias de sus pobladores, algunas almas en pena, animales que hablan, ángeles guardianes y hasta el mismo Dios, donde se mezcla la realidad con la fantasía. Una pieza literaria donde el microcosmos es un reflejo del macrocosmos. Esta novela fue publicada en el 2001 en España por la editorial Lumen bajo el título Un lugar llamado Antaño, edición ya descatalogada pero que ha sido rescatada por la editorial Anagrama que la publica en marzo del 2020 con el mismo título. ${ }^{(4)}$

4 https://www.anagrama-ed.es/libro/panorama-denarrativas / un-lugar-llamado-antano / 9788433980625 / PN_1026 accedido el 4 de marzo del 2020 
En 1998 publicó Dom dzienny, dom nocny (Casa de noche, casa de día), una novela que de acuerdo a los críticos no sigue un patrón lineal sino que está hecha de pequeños retazos narrativos que van desde las descripciones de la naturaleza hasta la historia de Santa Kummernis (o santa Liberada, la mujer cristiana que para no casarse con un pagano mudó su rostro femenino en masculino), cuasi ensayos o reflexiones que van construyendo una gran historia en una zona fronteriza entre Polonia y República Checa.

Luego de esta publicación, Tokarczuc publicó colecciones de cuentos y ensayos hasta el 2007 cuando publicó Bieguni, una "novela constelación" a juicio de la propia autora, utilizando la metáfora de las constelaciones estelares que en la antigüedad sugerían figuras zoomorfas o antropomorfas a los observadores; del mismo modo, la narración de pequeñas historias o microensayos que puestos en la órbita narrativa dan pie a la imaginación del lector para que construya una historia significativa para sí mismo. El nombre de Bieguni está tomado de una antigua secta eslava que utiliza el movimiento constante como freno a los ímpetus del Diablo como demiurgo. La novela fue traducida al inglés en el 2017 con el nombre de Flights y en español al año siguiente bajo el título de Los errantes. Por esta obra, recibió el Premio Literario Nike en Polonia, uno de los máximos galardones en las letras polacas, y el Man Booker Prize el 2018.

Los Errantes es una novela sobre la constancia del movimiento humano a través de las migraciones pedestres como a la vida actual de la circunvolución planetaria por medio del transporte aéreo. Describe desde el punto de vista antropológico y psicológico el comportamiento y pensamientos de los viajeros, de su estancia transitoria en los aeropuertos. Menciona un recuerdo de Borges, quien oyó escuchar una muy antigua tradición danesa, aquella dictada por la iglesia de que todo aquel que participara en una expedición al Polo Norte allanaría el camino a la salvación de su alma, y como se vio con el tiempo que pocos cumplían con tal precepto se convino en una rectificación de la proclama: cualquier viaje tendría el efecto salvador. Así, los seres humanos, en esta novela, se embarcan en un viaje perpetuo como los padres de la narradora que se asentaron en una zona de frontera y se desplazaban en un carro remolque hasta las fallidas expediciones de los cruzados. Pero a este viaje perpetuo se opone la constancia del cuerpo y en Los errantes se cuentan historias sobre la anatomía humana y la conservación de los cuerpos después de la muerte. Para tal fin se vale de múltiples historias, como la de Philipp Verheyen, un joven flamenco que prometió ser cura pero que un accidente provocó una infección de la pierna, luego una gangrena que no cedió a los cataplasmas para terminar en la amputación de su pierna lo que lo obligó a desertar de la vida monacal. Verheyen se dedicó a la medicina, pero aferrado a su cuerpo se encaró de conservar el miembro amputado en unos licores preparados por él mismo. Verheyen fue aun extraordinario alumno y no menos dibujante, copió el atlas anatómico de Vesalio y fue muy ducho en la disección, años después fue profesor:

"Los estudiantes tenían una alta estima de su firmeza y la precisión de sus conocimientos. Observaban los movimientos rápidos de su estilete como se observa un milagro. Dibujar nunca equivale a reproducir: para ver, hay que saber mirar, hay que saber qué se mira.". ${ }^{(5)}$

Verheyen era un maestro de la disección y sus ansias de conocimiento lo llevaron a disecar

5 Tokarczuc, O. Los errantes. Editorial Anagrama. Barcelona , 2019 pp: 191 
su pierna amputada, se sabe que tenía lo que ahora se llama el dolor del miembro fantasma y lo nombró como tal pero no se atrevía a hacerlo público para que no lo creyeran loco. En 1693, Verheyen publicó Corporis humani anatomiae, un atlas compendio de su experiencia de veinte años como anatomista. Aquel libro tuvo varias ediciones. Verheyen fue un gran creyente en la resurrección de los muertos y por eso conservó su pierna hasta el final de sus días. Lamentablemente, sus deudos lo enterraron sin pierna. Póstumamente, quedaron unos escritos sueltos denominados Cartas a mi pierna amputada, donde relata su dolor del miembro fantasma, se encuentra la primera descripción de Chorda Achillis o tendón de Aquiles, que el cuerpo y el alma son la misma cosa, así como la conclusión que el mismo Verheyen hace de su vida, un viaje constante por el interior de su cuerpo confeccionando los mapas más detallados del mismo utilizando sus ojos y el microscopio, para finalmente preguntarse "¿qué he estado buscando?".

"Los errantes" es una novela que incluye otras historias como las de la conservación del cadáver de Soliman, un sirviente y preceptor real, por parte del Emperador de Austria, que lo mostraba como un trofeo a sus invitados, se mencionan allí las cartas de su hija para recuperar el cadáver y darle cristiana sepultura. También se cuenta la historia de la colección de Frederik Ruysch, un eximio anatomista y conservador de piezas humanas en un museo que construyó a lo largo de treinta años, colocaba los restos humanos en dioramas, escenografías que reflejaban la esencia de la naturaleza humana hecha a base de huesos $\mathrm{u}$ órganos. A estas antiguas técnicas de conservación de órganos se juntan la de la moderna plastinación y la exhibición de cuerpos sin piel con el minucioso y expresivo detalle de vasos y músculos.
En este viaje constante a partir de mapas geográficos y anatómicos, al movimiento de personas o poblaciones se opone la naturaleza corporal como constancia. La vida que se opone a la muerte. Una novela, cuya lectura justifica con creces los premios recibidos.

Prowadź swój pług przez kości umartych (Pasa tu arado sobre los huesos de los muertos) publicada en 2009, es una novela aparentemente policial que no se embarca solamente en la mera investigación de encontrar al criminal sino también en alegatos sobre la defensa de la naturaleza y los animales. La protagonista y narradora es una fanática de la astronomía, los animales y los versos de William Blake, abriendo cada capítulo con un epígrafe extraído de una escena de El matrimonio del cielo y del infierno:

Aunque antes fue sumiso, al verse en una senda peligrosa el hombre justo entró al valle de la muerte.

He llegado a una edad y a un estado en que cada noche antes de acostarme debería lavarme los pies $y$ arreglarme a conciencia por si tuviera que venir a buscarme la ambulancia. Si aquella noche hubiera consultado el libro de las efemérides para saber qué sucedia en el cielo, jamás me hubiera ido a acostar. Pero en lugar de eso caí en un sueño profundo, gracias a una infusión de lúpulo que acompañé con dos grageas de valeriana. Por eso, cuando a mitad de la noche me despertaron los golpes en la puerta -violentos y desmesurados, y por lo tanto de mal augurio-, me costó recuperar la conciencia.

En las montañas de Silesia, una serie de crímenes de cazadores inicia la investigación criminal de la protagonista donde no solo se enfrenta a la cultura de la caza sino además a los conflictos de género. Ha sido publicada en español con el título de Sobre los huesos de los muertos. Este libro sirvió de base para la 
realización de la película Pokot (El rastro), dirigida por Agniezca Holland y cuyo guion fue hecho por la directora y la misma Tokarczuc, una obra que mereció el Oso de Plata del Festival de Berlín en 2017.

Ksiegi Jakubowe (Los libros de Jacob, 2014) es considerada la obra magna de Tokarczuc, de casi 1000 páginas, se sumerge en la vida y obra de Jakob Frank, procedente de Korolivka, antes parte del Reino Polonia-Lituania y hoy de la actual Ucrania. Frank, hijo de rabino y como tal tuvo acceso a los libros sagrados, pretendió una forma de mesianismo al intentar unir en una sola religión a judíos, musulmanes y cristianos a través de una relectura de la Cábala. En esta novela, Tokarczuc se mete en la mente de muchos personajes y a través de ellas describe la personalidad, intenciones e historia del nuevo mesías procedente de la región de Esmirna. Frank es perfilado literariamente como un salvador, como un hereje, como un revolucionario y como un embaucador. La rebelión que encaminó estuvo a punto de cambiar los destinos de Europa del este. Una novela totalizadora de múltiples lecturas, aun sin traducción al español.

Explorar la obra de Tokarczuc es encontrar novelas, ensayos y cuentos que explican las razones de la Academia Sueca para otorgarle el Premio Nobel 2018. A diferencia de la literatura de la Europa occidental, que es lineal, racional y reflexiva, a decir de la misma Tokarczuc, la literatura de Europa Central incorpora elementos místicos y mágicos que la hacen muy característica, sin dejar la esencia literaria de explicar al mundo y a la condición humana. Uno de sus cuentos, incluido en una antología europea y traducido al inglés -publicado por New Yorker- The ugliest woman in the world, es la historia de una mujer de aspecto repugnante:
Él se casó con la mujer más fea del mundo. Como conocido empresario circense hizo un viaje especial a Viena para conocerla. No fue un acto premeditado -nunca se le ocurrió de antemano que la haría su esposa. Pero una vez que la vio y toleró el primer susto no pudo quitarle la mirada de encima.

Una vez más la historia de vivir tránsito -la vida del circo- de atracción por lo teratológico y extraño, de lo que se esconde tras las apariencias -la máscara que postulaba Jung, del amor como acto de posesión, de los designios de la naturaleza y de un Dios creador, de las posibilidades de la realidad, nuestros deseos e imaginaciones.

Es en lo que se embarca Olga Tokarczuc, en las posibilidades de la imaginación humana, en la creación tanto de mitos como de ciencia, en los arquetipos humanos -otra vez Jung- que se repiten a través de la historia de la humanidad pero al mismo tiempo en la unidad dentro de la diversidad, en el constante designio de la humanidad de viajar alrededor del mundo para llevar al mismo tiempo civilización y barbarie, en la miopía humana de sentirse el centro de la naturaleza cuando solo somos una parte de ella, de la inmensidad y armonía del universo reflejada en las dimensiones infinitesimales del cuerpo humano, en la capacidad de la literatura para explicar el mundo y contar mentiras fabricadas para revelar la verdad.

Por eso creo que debo contar historias como si el mundo fuera una única entidad viva, que se transforma constantemente ante nuestros ojos como si fuera una pequeña pero al mismo tiempo poderosa parte de nosotros. ${ }^{(6)}$

6 https://www.nobelprize.org/prizes / literature/2018/ tokarczuk/lecture/ Accedido el 20 de febrero del 2020 
El movimiento constante que incluso tomó por sorpresa a la misma Olga Tokarczuc, la llamada de la Academia Sueca para informarle sobre el otorgamiento del remio Nobel, minutos antes de la conferencia de prensa en Estocolmo, la encontró manejando su automóvil en una carretera en dirección a Alemania, literalmente "cruzar las fronteras como una forma de vida".(7)

7 https://www.nobelprize.org/prizes / literature / 2018/ tokarczuk/interview/ Accedido el 28 de febrero del 2020
Acaso por ello, el movimiento constante, en Wroclaw, ciudad donde vive Olga Tokarczuc, a raíz del otorgamiento del Nobel, se declaró un día que todos aquellos que tuvieran un libro de la autora viajaban gratis en el tren.

La eterna constancia del movimiento.

\section{CORRESPONDENCIA:}

aldo.vivar.m@upch.pe

FECHA DE RECEPCIÓN: 04-03-2020.

FECHA DE ACEPTACIÓN: 11-03-2020. 